\title{
Lead removal in zinc leach residues from Kabwe, Zambia by carrier-in-pulp method using zero-valent iron
}

\author{
M. Silwamba ${ }^{1,2 *}$, M. Ito ${ }^{3}$, T. Fukushima ${ }^{1}$, I. Park ${ }^{3}$, S. Jeon ${ }^{3}$, C. B. Tabelin ${ }^{4}$, N. Hiroyoshi ${ }^{3}$ \\ 1) Division of Sustainable Resources Engineering, Graduate School of Engineering, Hokkaido University, Sapporo, \\ 060-8628, JAPAN \\ 2) Department of Metallurgy and Mineral Processing, School of Mines, The University of Zambia, P.O. Box 32379, \\ Lusaka, ZAMBIA \\ 3) Division of Sustainable Resources Engineering, Faculty of Engineering, Hokkaido University, Kita-Ku, Sapporo 060- \\ 8628, JAPAN \\ 4) School of Minerals and Energy Resources Engineering, The University of New South Wales, Sydney, NSW 2052, \\ Australia \\ * corresponding author: smarthias11@gmail.com
}

\begin{abstract}
Zinc leach residues (ZLRs) are hazardous materials because they contain toxic heavy metals such as lead $(\mathrm{Pb})$ and pose serious risks to the ecosystem and people living nearby. This study investigated $\mathrm{Pb}$ removal from ZLRs collected from Kabwe (Zambia), one of the most Pb-polluted towns in the world, using carrier-in-pulp method. ZLRs and zero-valent iron (ZVI), which was used as the carrier, were simultaneously mixed in $\mathrm{NaCl}$ solution. $\mathrm{Pb}$ was extracted from ZRLs and formed $\mathrm{Pb}$-chloride complexes, which was reductively precipitated as $\mathrm{Pb}^{0}$ on ZVI. The Pb-loaded ZVI was then separated from the leach pulp by magnetic separation. $\mathrm{Pb}$ removal was evaluated under various conditions such as leaching time, ZVI dosage and solution composition. The maximum $\mathrm{Pb}$ removal from ZLRs (about $78 \mathrm{wt} \% \mathrm{~Pb}$ ) was collated with $\mathrm{Pb}$ bound to acid leachable solid phases determined by sequential extraction. Comparing $\mathrm{Pb}$ removal when ZLRs were leached with and without the addition of ZVI, it was found that the addition of ZVI significantly improved the removal of $\mathrm{Pb}$ at low concentrations of $\mathrm{NaCl}$.
\end{abstract}

Keywords: lead, zero-valent iron, zinc leach residues

\section{INTRODUCTION}

Zinc $(\mathrm{Zn})$ is a widely utilized metal owing to its application in cosmetics, healthcare, dry batteries, corrosion protection as a sacrificial anode, and construction $^{1)}$. Zinc extraction processes depend on the mineralogy of the ore. For example, roasting-leachingelectrowinning processes is used for zinc sulfide minerals while direct leaching-electrowinning processes are typically applied to zinc oxide minerals. Zinc sulfide or oxide minerals usually occur with 'sister' lead minerals. During the leaching stage, enormous amounts of solid wastes called zinc leach residues (ZLRs) are generated that contain significant amounts of lead $(\mathrm{Pb})$ and $\mathrm{Zn}$. The high amounts of valuable metals in ZLRs make these solid waste materials to have an economic importance especially recently when high-grade ores have depleted. However, these materials pose serious environmental threats to ecosystem and human beings owing to the amounts of toxic metal, $\mathrm{Pb}$, that causes numerous disorders and diseases.

Hydrometallurgical processes have been applied to recover or remove $\mathrm{Pb}$ from ZLRs for the detoxification of these materials as well as for the $\mathrm{Pb}$ metal sustainability as it is still used in acid batteries ${ }^{2}$. These hydrometallurgical processes usually start with leaching followed by filtration, and the recovery of dissolved metals from the filtrate after purification. The disadvantages of this traditional approach of $\mathrm{Pb}$ removal from ZLRs are the use of highly concentrated leaching solutions, the very long process flow and above all, the generation of residues that contain residual solutions of toxic $\mathrm{Pb}$ due to the inherently incomplete solid-liquid separation encountered with very fine particles. To overcome this, extensive washing or stabilization of residues before disposal should be carried out. These challenges can be addressed by the addition of a 'carrier' during leaching that can sequester extracted $\mathrm{Pb}$ from leach pulp directly and separated from the suspension before filtration. Our laboratory has developed this new approach called carrier-in-pulp (CIP) method ${ }^{3}$. One good carrier for $\mathrm{Pb}^{2+}$ is zero-valent iron (ZVI) because of its lower standard redox potential than $\mathrm{Pb}$ that allows this material to sequester dissolved $\mathrm{Pb}$ via reductively precipitation (i.e., cementation). Pb-loaded ZVI, which is magnetic, can then be separated from the leach pulp using a magnet. CIP has been previously applied to remove $\mathrm{Pb}$ from municipal solid waste (MSW) molten fly ash. This solid waste contains lower concentration of $\mathrm{Pb}$, which is found in easier to dissolve phases compared with those found in ZLRs.

This study investigated the removal of $\mathrm{Pb}$ from ZLRs obtained Kabwe, Zambia, one of the most highly Pbpolluted town in the world, using the CIP approach. To understand the solid-phase partitioning of $\mathrm{Pb}$ and $\mathrm{Zn}$ in 
ZLRs, sequential extraction was carried out to supplement the mineralogical characteristics obtained by X-ray powder diffraction (XRD). The effects of ZVI dosage, time and solution composition on $\mathrm{Pb}$ removal were also elucidated.

\section{MATERIALS AND METHODS}

\subsection{Materials}

ZLRs composed were air-dried for 30 days in the laboratory before being dry-sieved using stainless steel sieves to obtain $-106 \mu \mathrm{m}$ fraction. The elemental compositions of ZLR samples were determined by X-ray fluorescence spectroscopy (XRF, EDXL 300, Rigaku Corporation, Japan) and inductively coupled plasma atomic emission spectroscopy (ICP-AES, ICPE-9820, Shimadzu Corporation, Japan) after aqua regia $\left(3 \mathrm{HCl}: 1 \mathrm{HNO}_{3} \mathrm{v} / \mathrm{v}\right.$ ) digestion using a microwave-assisted acid digestion system. XRD (MultiFlex, Rigaku Corporation, Japan) was used to analyze the mineralogical composition of the samples. Reagent grade sodium chloride and hydrochloric acid (Wako Pure Chemical Industries, Ltd., Japan) were used to prepare the leaching solutions of different compositions. Ultrapure ZVI (>99.9\%, $-150 \mu \mathrm{m}$, Wako Pure Chemical Industries, Ltd., Japan) was selected to sequester $\mathrm{Pb}^{2+}$ from the pulp via reductive precipitation.

\subsection{Methods}

\subsubsection{Sequential extraction}

The solid-phase partitioning of $\mathrm{Pb}, \mathrm{Zn}$ and iron $(\mathrm{Fe})$ in ZLRs was investigated by sequential extraction based on the procedure adapted from Dold ${ }^{4}$. This was done to understand solid-phase partitioning of $\mathrm{Pb}, \mathrm{Zn}$ and $\mathrm{Fe}$ amenable to acid leaching. Table 1 shows the details of the different lixiviants and experimental conditions used at each extraction stage as well as their target phases. In the first stage, $3 \mathrm{~g}$ of ZLRs were mixed with $120 \mathrm{~mL}$ of deionized (DI) in $300 \mathrm{~mL}$ Erlenmeyer flask placed in a thermostat water bath shaker and shaken at $200 \mathrm{rpm}$ for $4 \mathrm{~h}$. After shaking, solid-liquid separation was done by centrifugation at $3000 \mathrm{rpm}$ for 20 minutes. The supernatant was filtered through syringe-driven membrane filters with a pore size of $0.20 \mu \mathrm{m}$. The filtrate was analyzed for its $\mathrm{Pb}, \mathrm{Zn}$ and $\mathrm{Fe}$ concentrations using ICP-EAS. The residue was washed with $10 \mathrm{~mL}$ of DI water before the next extraction stage step. The same procedure was applied to all the extraction stages except for the last one $\left(5^{\text {th }}\right.$ stage $)$. In the $5^{\text {th }}$ stage, the residue was dissolved in aqua regia using a microwave-assisted acid digestion system (Ethos Advanced Microwave Lab station, Milestone Inc., USA).

\subsubsection{Leaching experiments with and without the addition of zero-valent iron}

Batch leaching experiments for $\mathrm{Pb}$ extraction from ZLRs were carried out using $200 \mathrm{~mL}$ Erlenmeyer flasks and the solution volume was fixed to $50 \mathrm{~mL}$ for all experiments. $\mathrm{NaCl}$ solutions of varying concentrations $(0-5.13 \mathrm{M})$ and $\mathrm{HCl}$ of different concentrations $(0.01-0.1 \mathrm{M})$ were added in the flasks and purged with ultrapure $\mathrm{N}_{2}$ for 10 minutes prior to the addition of ZLRs only or addition of both ZLRs and ZVI addition. $2.5 \mathrm{~g}$ of ZLRs with and without ZVI were added in the flasks containing the leaching solution. $\mathrm{N}_{2}$ purging of the pulp after sample addition was carried out for 5 minutes before sealing the flasks with silicon stoppers. The flasks were then shaken in a thermostat water bath shaker at $25^{\circ} \mathrm{C}$ at a shaking speed of 125 strokes/min and amplitude of $40 \mathrm{~mm}$. At the end of each shaking experiment, the leach pulp was collected, filtered through syringedriven membrane filter (pore size, $0.20 \mu \mathrm{m}$ ) and analyzed for its $\mathrm{Pb}$ concentration using ICP-AES. When ZLRs and ZVI were simultaneously leached together, separation of magnetic fractions (Pb-loaded ZVI) from the pulp was carried out using a handheld $0.6 \mathrm{~T}$ magnet. The magnetic fractions were then thoroughly washed with DI water and dried in a vacuum drying oven at $40^{\circ} \mathrm{C}$ for $24 \mathrm{~h}$. After drying, the magnetic fractions were digested in aqua regia and the concentrations of $\mathrm{Pb}, \mathrm{Zn}$ and $\mathrm{Fe}$ were quantified. The magnetic fractions were also analyzed by scanning electron microscopy equipped with an energy dispersive X-ray spectroscopy (SEM-EDX; JSM-IT200, JEOL Ltd., Japan).

Table 1.Procedure and lixiviants applied for targeted solidphase in sequential extraction.

\begin{tabular}{|c|c|c|}
\hline Stage & Target phase(s) & Extracting reagent(s)/condition \\
\hline 1 & Water-soluble & $\begin{array}{l}\text { Deionized water }(200 \mathrm{rpm}, 4 \mathrm{~h} \\
\left.\text { and } 25^{\circ} \mathrm{C}\right) .\end{array}$ \\
\hline 2 & Carbonates & $\begin{array}{l}1 \mathrm{M} \text { sodium acetate pH } 5(200 \\
\left.\mathrm{rpm}, 4 \mathrm{~h} \text { and } 25^{\circ} \mathrm{C}\right) .\end{array}$ \\
\hline 3 & $\begin{array}{l}\text { Amorphous } \\
\text { Fe/Mn } \\
\text { oxyhydroxides }\end{array}$ & $\begin{array}{l}0.12 \mathrm{M} \text { oxalic acid }+0.13 \mathrm{M} \\
\text { ammonium oxalate }(200 \mathrm{rpm} \text {, } \\
\left.6 \mathrm{~h}, 25^{\circ} \mathrm{C} \text { in the dark }\right) .\end{array}$ \\
\hline 4 & $\begin{array}{l}\text { Crystalline Fe- } \\
\text { oxides }\end{array}$ & $\begin{array}{l}0.3 \mathrm{M} \text { trisodium citrate }+0.2 \mathrm{M} \\
\text { sodium hydrogen carbonate }+ \\
\text { sodium dithionite ( } 200 \mathrm{rpm}, 85 \\
{ }^{\circ} \mathrm{C} \text {, until the brownish color } \\
\text { disappears). }\end{array}$ \\
\hline 5 & Residual & $\begin{array}{l}\text { Aqua regia (heat to } 220^{\circ} \mathrm{C} \text { for } \\
20 \mathrm{~min} \text { and hold for } 30 \mathrm{~min} \text { ). }\end{array}$ \\
\hline
\end{tabular}

\section{RESULTS AND DISCUSSION}

\subsection{Elemental and mineralogical characteristics of zinc leach residues}

Results of elemental composition analyses by ICP-AES after aqua regia digestion and XRF (Table 2) showed that ZLRs sample contains high amounts of $\mathrm{Pb}(6.19 \mathrm{wt} \%), \mathrm{Zn}$ (2.53 wt\%), Fe (17.02 wt\%), $\mathrm{Ca}(7.3 \mathrm{wt} \%)$, and $\mathrm{SiO}_{2}(31.43$ $\mathrm{wt} \%)$. The residues also contain small amounts of $\mathrm{Cu}(0.21$ 
wt \%), $\mathrm{Al}_{2} \mathrm{O}_{3}(2.9$ wt \%), and other elements.

Table 2. Chemical composition of zinc leach residues.

\begin{tabular}{|c|c|c|c|}
\hline \multicolumn{2}{|c|}{$\begin{array}{l}\text { Metal } \\
\text { composition by } \\
\text { ICP-AES analysis }\end{array}$} & \multicolumn{2}{|c|}{$\begin{array}{l}\text { Elemental oxide } \\
\text { composition by XRF } \\
\text { analysis }\end{array}$} \\
\hline Metal & $\%$ & $\begin{array}{l}\text { Element } \\
\text { oxide }\end{array}$ & $\%$ \\
\hline $\mathrm{Pb}$ & 6.19 & $\mathrm{PbO}$ & 6.48 \\
\hline $\mathrm{Zn}$ & 2.53 & $\mathrm{ZnO}$ & 3.28 \\
\hline $\mathrm{Fe}$ & 17.02 & $\mathrm{Fe}_{2} \mathrm{O}_{3}$ & 24.3 \\
\hline $\mathrm{Cu}$ & 0.21 & $\mathrm{CuO}$ & 0.25 \\
\hline \multirow[t]{8}{*}{$\mathrm{Ca}$} & 7.3 & $\mathrm{CaO}$ & 10.57 \\
\hline & & $\mathrm{SiO}_{2}$ & 31.43 \\
\hline & & $\mathrm{Al}_{2} \mathrm{O}_{3}$ & 2.89 \\
\hline & & $\mathrm{SO}_{3}$ & 18.17 \\
\hline & & $\mathrm{V}_{2} \mathrm{O}_{5}$ & 0.72 \\
\hline & & $\mathrm{MnO}$ & 0.25 \\
\hline & & $\mathrm{P}_{2} \mathrm{O}_{5}$ & 0.54 \\
\hline & & $\mathrm{ZrO}_{2}$ & 0.59 \\
\hline
\end{tabular}

Minerals such as gypsum $\left(\mathrm{CaSO}_{4} \cdot 2 \mathrm{H}_{2} \mathrm{O}\right)$, anglesite $\left(\mathrm{PbSO}_{4}\right)$, zinc sulfate dihydrate $\left(\mathrm{ZnSO}_{4} \cdot 2 \mathrm{H}_{2} \mathrm{O}\right)$, quartz $\left(\mathrm{SiO}_{2}\right)$, and goethite $(\mathrm{FeO}(\mathrm{OH}))$ were detected by XRD analysis (results not shown). During sulfuric acid leaching, dissolved $\mathrm{Pb}^{2+}$ from lead oxide minerals precipitated as $\mathrm{PbSO}_{4}$, which explains why anglesite was present in the ZLRs. Additionally, $\mathrm{PbSO}_{4}$ could also be formed via the weathering of galena $(\mathrm{PbS})$ to lead oxide and further converted to anglesite ${ }^{5)}$. Similar to $\mathrm{PbS}$ weathering, $\mathrm{ZnS}$ in the residues could have weathered and transformed to $\mathrm{ZnSO}_{4} \cdot 2 \mathrm{H}_{2} \mathrm{O}$. Physical entrapment of solution $\left(\mathrm{ZnSO}_{4}\right)$ during filtration of zinc leach pulp may also have contributed to the formation of $\mathrm{ZnSO}_{4} \cdot 2 \mathrm{H}_{2} \mathrm{O}^{6}$.

\subsection{Solid-phase partitioning of lead, zinc and iron}

The solid-phase partitioning of $\mathrm{Pb}, \mathrm{Zn}$ and $\mathrm{Fe}$ in the ZLRs sample is shown in Fig. 1. Pb was mostly associated with two fractions: $66 \%$ of $\mathrm{Pb}$ was partitioned with the acid-soluble fraction (i.e., exchangeable and carbonates), and $33 \%$ of $\mathrm{Pb}$ was associated with the residual phases, which in this study denotes those found with sulfides and silicates). High amounts of acid soluble $\mathrm{Pb}$ fraction in ZLRs may be attributed to $\mathrm{PbSO}_{4}$ mineral which was detected by XRD. Previous research on $\mathrm{Pb}$ speciation from $\mathrm{PbSO}_{4}$ showed that $\mathrm{Pb}$ fractionated in huge amounts at the acid-soluble stage with very low amounts in preceding and succeeding extraction stages which is in agreement with results obtained in this study ${ }^{7)}$.

Unlike $\mathrm{Pb}$ that was mainly partitioned with two of the five operationally defined solid-phases, $\mathrm{Zn}$ was associated in all solid-phases in the following in order of abundance: crystalline Fe/Mn-oxides $>$ amorphous Fe/Mnoxyhydroxides $\approx$ carbonates $>$ residual $>$ water-soluble phases. High fractions of $\mathrm{Zn}$ extracted under reducing conditions were obtained (, i.e., 27\% at amorphous Fe-oxide and $33 \%$ crystalline Fe-oxide stage), which is similar to those reported by Sethurajan et al. ${ }^{8)}$ using ZLRs from Brazil. The association of $\mathrm{Zn}$ with reducible fractions could be attributed to co-precipitation or encapsulation within $\mathrm{Fe}$ oxide/oxyhydroxide phases.

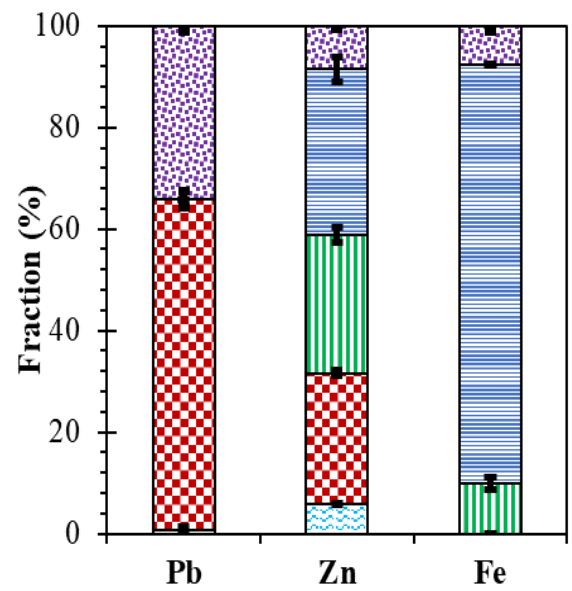

장 Residual (with sulfides, organics and silicates)

目 With crystalline $\mathrm{Fe}$ (III) oxides

प With amorphous Fe-oxides and $\mathrm{MnO}$

๑ With carbonates and exchangeables

因 With water soluble

Fig. 1. Solid-phase partitioning of lead, zinc and iron in ZLRs.

From the solid-phase partitioning results, it was shown that ZLRs contain significant amounts of $\mathrm{Pb}$ and $\mathrm{Zn}$ in the acidleachable fraction, indicating that ZLRs should be regarded as environmentally hazardous materials. Looking at it from another perspective, the results also show that ZLRs can be considered as secondary sources of $\mathrm{Pb}$ and $\mathrm{Zn}$ as they contain significant amounts of these metals in easily extractable fractions.

\subsection{Lead removal from zinc leach residues}

Fig. 2 illustrates the concentration of $\mathrm{Pb}$ in solution as a function of time when $2.5 \mathrm{~g}$ of ZLRs was leached in a 50 $\mathrm{mL}$ solution containing $5.13 \mathrm{M}(300 \mathrm{~g} / \mathrm{L}) \mathrm{NaCl}$ and $0.05 \mathrm{M}$ $\mathrm{HCl}$ with and without the addition of $0.5 \mathrm{~g} \mathrm{ZVI}$. When ZLRs were leached in the absence of ZVI, the concentration of $\mathrm{Pb}$ in solution increased with time and stabilized at around $10.4 \mathrm{mM}$ after $2 \mathrm{~h}$, suggesting that apparent equilibrium was reached. When ZLRs were leached with $\mathrm{ZVI}$, the concentration of $\mathrm{Pb}$ in solution initially increased with time up to $8.8 \mathrm{mM}$, but after this, $\mathrm{Pb}$ concentration decreased drastically below $0.5 \times 10^{-6} \mathrm{mM}(0.01 \mathrm{mg} / \mathrm{L})$ after $12 \mathrm{~h}$. Pb extraction from ZLRs likely occurred via chemical reaction (1) while chemical reaction (2) might explain why $\mathrm{Pb}$ concentration decreased in the presence of $\mathrm{ZVI}$. 
$\mathrm{PbSO}_{4}+\mathrm{xCl}^{-} \rightarrow \mathrm{PbCl}_{\mathrm{x}}^{-(\mathrm{x}-2)}+\mathrm{SO}_{4}^{2-}$

$\mathrm{PbCl}_{\mathrm{x}}^{-(\mathrm{x}-2)}+\mathrm{Fe} \rightarrow \mathrm{Pb}+\mathrm{Fe}^{2+}+\mathrm{xCl}^{-}$

Here $\mathrm{x}=1,2,3,4$ and $\mathrm{PbCl}_{\mathrm{x}}^{-(\mathrm{x}-2)}$ is lead chloride complexes.

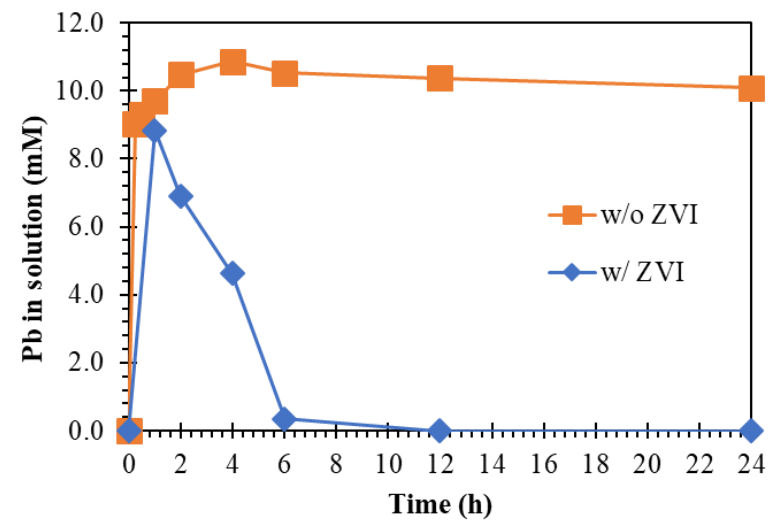

Fig. 2. Fig. 2. Effects of time on $\mathrm{Pb}$ dissolution from ZLRs with and without ZVI.

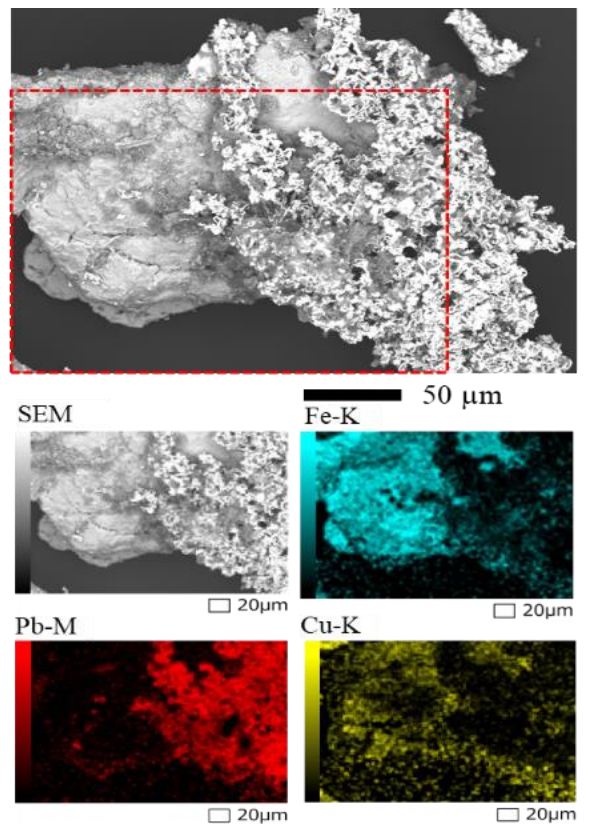

Figure 3. Fig. 3. SEM microphotograph and EDX elemental maps of the magnetic fraction after the carrier in pulp technique.

Because the drastic decrease of $\mathrm{Pb}$ concentration occurred only after $2 \mathrm{~h}$, there is a lag time prior to the start of reductive precipitation (reaction 2 ). This lag time may be related to the removal of the oxide film on ZVI and the need to attain a critically large cathodic area (deposit of $\mathrm{Pb}$ on the surface of $\mathrm{Fe}$ ) for reductive precipitation ${ }^{9}$.
To confirm that reductive precipitation of $\mathrm{Pb}^{2+}$ occurred on the surface of ZVI, the magnetic fractions obtained after $12 \mathrm{~h}$ of leaching ZLRs with ZVI were analyzed by SEMEDX (Fig. 3). The elemental maps illustrate that $\mathrm{Pb}$ as well as $\mathrm{Cu}$ were extracted from ZLRs and cemented on the surface of ZVI.

Fig. 4 shows the effects of ZVI dosage on the $\mathrm{Pb}$ distribution to three different fractions (solution, ZVI (magnetic fraction), and residues (non-magnetic fraction or un-leached $\mathrm{Pb}$ in ZLRs)) when ZLRs were leached together with ZVI in solution containing $5.13 \mathrm{M}$ and $0.05 \mathrm{M} \mathrm{HCl}$ for $12 \mathrm{~h}$. Substantial amounts of $\mathrm{Pb}$ remained in solution when $0.05 \mathrm{~g}$ ZVI was added. This may be attributed to insufficient $\mathrm{ZVI}$ to reduce $\mathrm{Pb}^{2+}$ to metallic $\mathrm{Pb}$. Although the mole ratio of ZVI to total $\mathrm{Pb}$ in $2.5 \mathrm{~g}$ ZLRs was stoichiometry sufficient to reduce all $\mathrm{Pb}^{2+}$, unnecessary ZVI consumption may have occurred via side chemical reactions. These side reactions may involve oxide film removal on ZVI (Eq. 3), consumption of ZVI via reactions with ferric ions (Eq. 4), oxidation of cemented $\mathrm{Pb}$ to $\mathrm{Pb}^{2+}$ by the ferric ions (Eq. 5), and dissolution of ZVI through proton-promoted attack (Eq. $6)$.

$$
\begin{aligned}
& \mathrm{Fe}_{2} \mathrm{O}_{3}+6 \mathrm{H}^{+} \rightarrow \mathrm{Fe}^{3+}+3 \mathrm{H}_{2} \mathrm{O} \\
& \mathrm{Fe}+2 \mathrm{Fe}^{3+} \rightarrow 3 \mathrm{Fe}^{2+} \\
& \mathrm{Pb}+2 \mathrm{Fe}^{3+} \rightarrow \mathrm{Pb}^{2+}+2 \mathrm{Fe}^{2+} \\
& \mathrm{Fe}+2 \mathrm{H}^{+} \rightarrow \mathrm{Fe}^{2+}+\mathrm{H}_{2}
\end{aligned}
$$

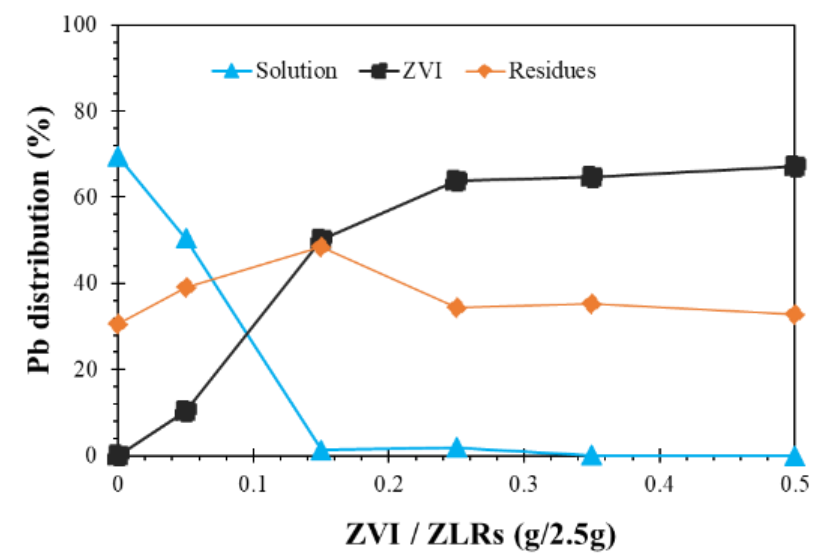

Fig. 4. Effects of ZVI dosage on the distributions of $\mathrm{Pb}$ in solution, ZVI (magnetic fraction), and residues after $12 \mathrm{~h}$ of leaching.

Fig. 5 shows the effects of solution composition on $\mathrm{Pb}$ removal when $2.5 \mathrm{~g}$ ZLRs were leached together with 0.35 $\mathrm{g}$ ZVI for $12 \mathrm{~h}$. The amount of ZVI used in this series of experiments was decided based on the results shown in Fig. 4. Here, $\mathrm{Pb}$ removal when ZLRs were leached without the 
addition of ZVI is referred to in percentage of total $\mathrm{Pb}$ in ZLRs that dissolved in solution, whereas when ZLRs and $\mathrm{ZVI}$ were added together, $\mathrm{Pb}$ removal corresponds to the amount of $\mathrm{Pb}$ cemented on ZVI because almost $100 \%$ of dissolved $\mathrm{Pb}$ was recovered as metal deposited on ZVI after $12 \mathrm{~h}$.
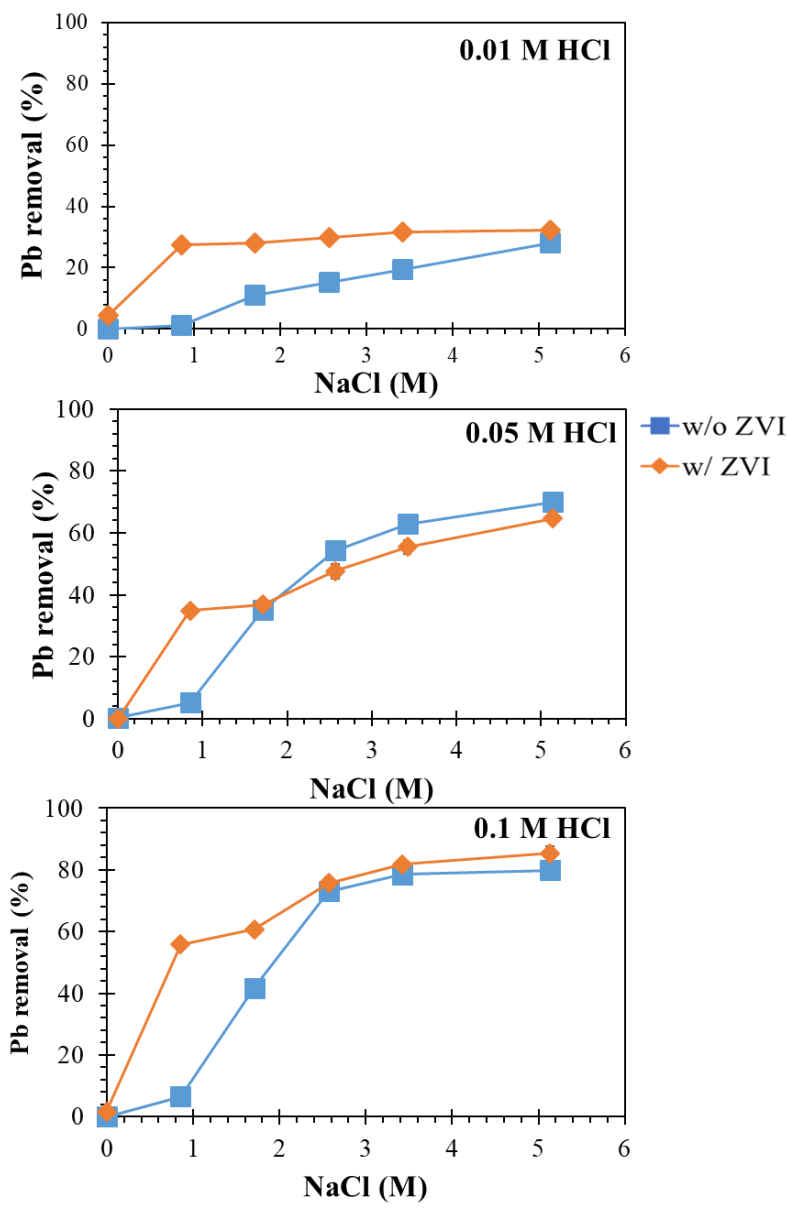

Fig. 5. Effects of solution composition on $\mathrm{Pb}$ removal when ZLRs were leached with and without $0.35 \mathrm{~g} \mathrm{ZVI}$ for $12 \mathrm{~h}$.

Fig. 5 shows that $\mathrm{Pb}$ removal increased with increasing concentration of $\mathrm{HCl}$ and $\mathrm{NaCl}$, regardless of whether or not ZVI was present in the system. The highest $\mathrm{Pb}$ removal reached around $78 \%$ of the total $\mathrm{Pb}$ in ZLRs at $0.1 \mathrm{M} \mathrm{HCl}$ and $\mathrm{NaCl}$ concentration of over $3.4 \mathrm{M}$. The higher amounts of $\mathrm{Pb}$ extracted in comparison to that determined by sequential extraction (66\%) may be attributed to the dissolution of $\mathrm{Pb}$ associated with sulfide/organic at high $\mathrm{H}^{+}$ and $\mathrm{Cl}^{-}$concentration.

The relationship between increasing $\mathrm{NaCl}$ concentration and $\mathrm{Pb}$ removal could be explained by the formation of soluble lead chloride complexes as the concentration of chloride $\left(\mathrm{Cl}^{-}\right)$increases (Eq. 1). Increasing the $\mathrm{HCl}$ concentration in $\mathrm{NaCl}$ solution not only increased the concentration of $\mathrm{Cl}^{-}$but also that of $\mathrm{H}^{+}$, which enhanced the dissolution of $\mathrm{PbSO}_{4}$ and $\mathrm{CaSO}_{4} \cdot 2 \mathrm{H}_{2} \mathrm{O}$ minerals. ZLRs contain significant amounts of $\mathrm{CaSO}_{4} \cdot 2 \mathrm{H}_{2} \mathrm{O}$ (from XRD analysis) which may have covered the surface of $\mathrm{PbSO}_{4}$. The solubility of $\mathrm{CaSO}_{4} \cdot 2 \mathrm{H}_{2} \mathrm{O}$ in $\mathrm{NaCl}$ solution has been found to increase with increase not only $\mathrm{Cl}^{-}$but also $\mathrm{H}^{+}$. However, there is an optimum $\mathrm{Cl}^{-}$concentration beyond which dissolution of $\mathrm{CaSO}_{4} \cdot 2 \mathrm{H}_{2} \mathrm{O}$ starts to decrease $\operatorname{again}^{10)}$.

It is noteworthy that the addition of ZVI promoted $\mathrm{Pb}$ extraction even at low concentrations of $\mathrm{NaCl}$. Without $\mathrm{ZVI}$, the solution becomes saturated with dissolved $\mathrm{Pb}$ and once this threshold is reached, further $\mathrm{Pb}$ dissolution from ZLRs becomes negligible. When ZVI is present, however, the recovery from the solution of dissolved $\mathrm{Pb}^{2+}$ as elemental $\mathrm{Pb}$ prevents the solution from reaching saturation, a condition that promoted the dissolution of $\mathrm{Pb}$ from ZLRs.

\section{CONCLUSIONS}

This study investigated $\mathrm{Pb}$ removal from ZLRs by extracting $\mathrm{Pb}$ into solution, recovering the extracted $\mathrm{Pb}^{2+}$ by reductive precipitation on ZVI, and separation from the leach pulp by a magnet. A summary of the findings are as follows:

1. The addition of ZVI during leaching of ZLRs increased $\mathrm{Pb}$ removal even at a low concentration of $\mathrm{NaCl}$. This increase was attributed to the recovery of dissolved $\mathrm{Pb}$ by ZVI that prevented the leach solution from attaining saturation.

2. The generated leach solution contains less than 0.01 $\mathrm{mg} / \mathrm{L}$ of dissolved $\mathrm{Pb}$ when ZLRs were leached in the presence of ZVI. This approach to detoxification of ZLRs removes the need for extensive washing of the generated residues to remove this toxic heavy metal.

3. At higher $\mathrm{HCl}$ addition, $\mathrm{Pb}$ removal increased by $12 \%$, which was higher than the determined labile $\mathrm{Pb}$ in ZRLs by sequential extraction. This increase is ascribed to the $\mathrm{H}^{+}$-promoted and $\mathrm{Cl}^{-}$-enhanced dissolution $\mathrm{Pb}$-containing sulfide/organic phases.

\section{References}

1. Graedel TE, Beers D van, Bertram M, et al. The Multilevel Cycle of Anthropogenic Zinc. Journal of Industrial Ecology. 2005;9(3):67-90.

2. Turan MD, Altundoğan HS, Tümen F. Recovery of zinc and lead from zinc plant residue. Hydrometallurgy. 2004;75(1):169-176.

3. Alorro RD, Mitani S, Hiroyoshi N, Ito M, Tsunekawa M. Recovery of heavy metals from MSW molten fly ash by carrier-in-pulp method: Fe powder as carrier. Minerals Engineering. 2008;21(15):1094-1101. 
4. Dold B. Speciation of the most soluble phases in a sequential extraction procedure adapted for geochemical studies of copper sulfide mine waste. Journal of Geochemical Exploration. 2003;80(1):5568.

5. Heidel C, Tichomirowa M. Galena oxidation investigations on oxygen and sulphur isotopes. Isotopes in Environmental and Health Studies. 2011;47(2):169-188.

6. Ru Z, Pan C, Liu G, Wang X, Dou G, Zhu K. Leaching and recovery of zinc from leaching residue of zinc calcine based on membrane filter press. Transactions of Nonferrous Metals Society of China. 2015;25(2):622-627.

7. Leinz R., Sutley S., Desborough G., Briggs P. An Investigation of the Partitioning of Metals in Mine Wastes Using Sequential Extractions. In: Proceedings from the Fifth International Conference on Acid Rock Drainage. Vol 2. Colorado USA: Society for Mining, Metallurgy, and Exploration; 2000:1489-1499.

8. Sethurajan M, Huguenot D, Lens PNL, Horn HA, Figueiredo LHA, van Hullebusch ED. Fractionation and leachability of heavy metals from aged and recent $\mathrm{Zn}$ metallurgical leach residues from the Três Marias zinc plant (Minas Gerais, Brazil). Environ Sci Pollut Res. 2016;23(8):7504-7516.

9. Chen HJ, Lee C. Effects of the type of chelating agent and deposit morphology on the kinetics of the copperaluminum cementation system. Langmuir. 1994;10(10):3880-3886.

10. Shukla J, Mohandas VP, Kumar A. Effect of $\mathrm{pH}$ on the Solubility of $\mathrm{CaSO} 4 \cdot 2 \mathrm{H} 2 \mathrm{O}$ in Aqueous $\mathrm{NaCl}$ Solutions and Physicochemical Solution Properties at $35{ }^{\circ} \mathrm{C} . J$ Chem Eng Data. 2008;53(12):2797-2800. 